Studia Slavica Savariensia 2016. 1-2. 20-29

DOI: $10.17668 /$ SSS.2016.1-2.20

Габор Л. Балаж

(Сегед, Венгрия)

\title{
К МОРФОЛОГИЧЕСКОЙ ТИПОЛОГИИ СЛАВЯНСКИХ ЯЗЫКОВ
}

\begin{abstract}
General problems of the morphological typology of languages are, naturally, significant for Slavic linguistics, as well. In this paper a brief survey is presented of relevant current views and theories, including their applicability to Slavic linguistic research. In this respect, special attention is given to historical changes of the Bulgarian noun system.
\end{abstract}

Keywords: Typology, morphology, Slavic languages, Bulgarian

В лингвистической литературе для морфологической характеристики языков - в том числе и славянских - до сих пор очень часто употребляются термины агглютинативный, флективный, изолирующий и инкорпорирующий. Как известно, широкому распространению употребления названных терминов способствовала в первую очередь деятельность таких выдающихся языковедов 19 в. как Фридрих и Август фон Шлегель, Вильгельм фон Гумбольдт и Август Шлейхер. Несмотря на невероятную популярность данной типологической классификации, сравнительно рано начали проявляться и ее недостатки. Как справедливо отметил Гринберг: «Отличительные критерии отдельных типов никогда не определялись чётко и не употреблялись объективно» (перевод мой Г.Л.Б.) (GREENBERG 1960: 182). Кроме того, согласно классической классификации, любой язык должен был соответствовать только одному из четырех типов, независимо от того, в какой мере выступали определенные свойства в его отдельных системах и подсистемах. На несостоятельность такого подхода указал и Сепир, создав более удачную систему, в которой языки группируются по нескольким независимым признакам. Традиционные термины сохраняются, но они употребляются как четко определенные параметры, которые уже не представляют взаимоисключающие единицы: «Один язык может быть и агглютинативным, и флективным, или и флективным, и полисинтетическим, или даже полисинтетическим и изолирующим...» (перевод мой - Г.Л.Б.) (SAPIR 1921: 123). Хотя типологическая классификация Сепира тоже не была свободна от недостатков, что препятствовало ее широкому распространению, наверное не случайно, что Гринберг выработал свою известную квантитативную морфологическую типологию языков именно на основе несколько 
модифицированной классификации Сепира. Квантитативная типология Гринберга, однако, тоже не стала общепринятой, поэтому поиск новой, более убедительной теории продолжался. Возникает вопрос, как обстоит дело с этой проблемой в наши дни?

Немного суживая объект анализа, я сосредоточу внимание на современной интерпретации тех двух типов классической классификации, которые чаще всего выступают в связи с типологией европейских языков - агглютинации и флексии. Но так как вместо флексии более удачным и однозначным оказался термин фузия, в дальнейшем и я буду употреблять именно его. Итак, говоря об агглютинации и фузии, следует подчеркнуть, что эти категории не являются первичными и не поддаются эксплицитной дефиниции, так как они обе состоят из нескольких параметров. Однако единогласия относительно количества и сущности этих параметров нет, что осязаемо отражается на современной типологической литературе. Скаличка, например, приводит больше десяти признаков отдельно для агглютинации и фузии (СКАЛИЧКА 1966; SKALIČKA 1979: 36-54), в то время как Планк определяет одиннадцать пар параметров, где один член пары указывает на агглютинацию, а другой - на фузию (PLANK 1999: 282-284). Несомненно, что чем больше признаков, тем точнее можно определить языковые типы, но слишком много параметров нередко затрудняют анализ и осложняют интерпретацию результатов.

Новые исследования доказывают, что для однозначного установления типологической принадлежности достаточно оценивать не больше трехчетырех параметров. Плунгян разграничивает следующие черты, различающие агглютинацию от фузии: 1) отсутствие фузии; 2) инвариантность корней и аффиксов; 3) отсутствие кумуляции (т.е. накопления грамматической информации в окончании) (PLUNGIAN 2001: 669-673). К подобному заключению пришел и Хаспельмат, который предполагает, что для основательного эмпирического теста при разграничении агглютинативных и фузионных черт и определении их пропорций достаточно исследовать четыре параметра, а именно: 1) кумуляция $\sim$ сепарация; 2) чередование $\sim$ инвариантность корня; 3) чередование $\sim$ инвариантность аффиксов и 4) супплетивизм аффиксов (HASPELMATH 2009: 16-18). Очевидно, что параметры двух типологов, хотя и не совпадают полностью, вполне соизмеримы как между собой, так и с первыми тремя параметрами Планка, которыми являются: 1) сепарация $\sim$ кумуляция; 2) инвариантность $\sim$ вариантность и 3 ) различение омонимия грамматических категорий и их маркеров (PLANK 1999: 282). В последнее время подчеркивается значительность трех параметров: 1) степень фонологической фузии; 2) экспонентность (т.е. число категорий, накапливаемых в одном маркере; ср. кумуляция) и 3) флективность (т.е. вариантность $\sim$ инвариантность аффиксов) (BICKEL \& NICHOLS 2007: 172-193; VELUPILLAI 2012: 95-110). Данная тройка 
параметров принимается и авторским коллективом Всемирного атласа языковых структур (WALS).

В типологической системе т.н. естественной морфологии тоже значительную роль играют вышеуказанные параметры. Согласно этой теории, признаки, с помощью которых возможно описание любой словоизменительной системы, следующие:

(a) набор категориальных комплексов и категорий, примыкающих к ним;

(б) флексия, прикрепленная к основе, которая может функционировать как самостоятельное слово, или флексия, прикрепленная к основе, которая не может функционировать как самостоятельное слово (base-form inflection versus stem inflection);

(в) отдельное или комбинированное обозначение категорий;

(г) отсутствие или наличие типов синкретизма и их место внутри словоизменительных парадигм;

(д) типы маркеров, применяемых для обозначения отдельных морфосинтаксических категорий;

(е) наличие или отсутствие словоизменительных классов (WURZEL 1989: 74-77).

Нетрудно заметить, что приведенные шесть параметров не противоречат критериям Планка, Плунгяна, Хаспельмата и других, так как пункт (в) включает в себя сепарацию/кумуляцию, пункт (д) чередование/инвариантность корня или вариантность/инвариантность, пункт (е) - чередование/инвариантность аффиксов, инвариантность/вариантность, а пункт (г) - различение/омонимию грамматических категорий и их маркеров. Особенно важен первый пункт, по которому предполагается, что в грамматических системах нет универсальных категориальных комплексов и соответствующих категорий, поскольку они устанавливаются для каждой языковой системы отдельно (ср. ARONSON 2007: 17). Каждый язык представляет собой особую систему и «выбирает» свои свойства по всем шести параметрам. Так как эти свойства являются отличительными чертами отдельных морфологических систем, они называются системоопределяющими структурными признаками (system-defining structural properties).

На основе выше представленных типологических параметров языковеды независимо друг от друга подчеркивают, что в естественных языках агглютинативные и фузионные признаки проявляются в смешанном виде, а «чистые» типы реально не существуют. Даже турецкий язык, «эталон» агглютинирующих языков, имеет известное количество фузионных признаков в связи с инвариантностью его аффиксов. В типологическом анализе Хаспельмата турецкий - вместе с венгерским, но вслед за финским - занимает только четырнадцатое место 
среди тридцати языков различных групп. В другом конце списка латинский, который обыкновенно считается «типичным фузионным» языком, но по вариантности корня оказывается значительно более агглютинативным, чем, например, немецкий, арабский, венгерский или финский.

Благодаря многочисленным типологическим исследованиям вырисовался и другой, очень важный вывод, согласно которому нет обязательной корреляции между частными системами морфологии. Большое количество примеров показывает, что есть немало языков, именная система которых отличается от соответствующей глагольной системы по признаку агглютинативности/фузии. Следовательно, нет агглютинативных или фузионных языков, существуют лишь более или менее агглютинативные или фузионные (под)системы внутри отдельных языков.

В данном контексте интересное место занимает современный болгарский язык (вместе с македонским). Вследствие значительных исторических изменений в нем преобразовалась морфологическая система имен, в которой появились новые, изолирующие (аналитические) черты. В системе существительных и прилагательных изчезли падежи, а грамматические отношения вместо окончаний выражаются с помощью предлогов. Но как отражается это новое явление, отличающее болгарский (и македонский) от всех остальных славянских языков? Можно ли сказать, что он стал аналитическим языком? Чтобы убедительно ответить на этот вопрос, следует принять во внимание следующие обстоятельства.

Во-первых, сохранены такие фузионные признаки, как а) категория рода и обязательное согласование (не только у имен); б) вариантность флексий для выражения форм множественного числа; в) звательная форма; г) фузия типа юнак - юнаџи, бог - боже и т.д.; д) случаи перегласовки типа бряг - брегове, сянка - сенки и т.д.; д) вариантность нулевого окончания с $-u$ у некоторых прилагательных мужского рода в ед.

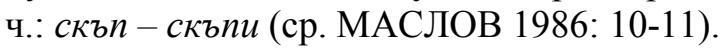

Во-вторых, вместе с утратой падежей в именной системе появились новые, агглютинативные признаки, которые тоже являются синтетическими средствами: а) в этом отношении некоторые языковеды указывают на употребление постпозитивного определенного члена (SKALIČKA 1979: 39-40; ГЕРДЖИКОВ 1987: 39-40); б) в области словообразования наблюдается множество агглютинативных способов и маркеров; в) частицы по- и най- являются практически исключительными маркерами степеней сравнения, причем они могут употребляться не только с прилагательными, но и с существительными, предложными сочетаниями и даже глаголами; г) Маслов убедительно констатирует, что окончание мн. ч. - $и$ у прилагательных и причастий является стандартным и инвариантным. Хотя окончание относительных местоимений -то употребляется вне именной системы, оно тем не менее представляет 
очень типичный пример инвариантного маркера (ср. МАСЛОВ 1986: 1213).

Приведенные факты не позволяют считать именную систему современного болгарского языка полностью аналитичной. Несмотря на некоторые признаки изолирующего типа (напр., отсутствие падежей) болгарский язык пока остался фузионным. Изменения отдельных его типологических параметров не привело к трансформации всей грамматической системы, а только к модификации одной (именной) подсистемы. В остальных подсистемах произошло гораздо меньше существенных изменений, причем они по-прежнему сохраняют - хоть частично - системоопределяющие структурные признаки древнеболгарской эпохи. Достаточно привести такие примеры, как сохранение отдельных падежей в системе местоимений, многочисленные случаи фузии, кумуляции и вариантности корня и аффиксов у глаголов, употребление аориста и имперфекта, отсутствующих в большинстве славянских языков и т.д. Несомненно, что некоторые типологические показатели аналитизма появляются и в названных подсистемах (ср. ГЕРДЖИКОВ 1983; 1987), но истинного перехода от синтетизма к аналитизму, конечно, и в этих случаях нет.

Морфологические отличия болгарской (и македонской) именной системы, по сути дела, противопоставляют ее именным системам всех остальных славянских языков, поскольку между последними нельзя выявить подобных существенных типологических различий. Иными словами, структурное разнообразие большинства славянских языков остается практически скрытым. В отличие от более успешной фонологической классификации, разработанной Бодуэном де Куртенэ и Якобсоном, до сих пор нет надежной морфологической классификации славянских языков. Хотя есть попытки группировать эти языки по отдельным морфологическим маркерам, целостной типологической системы пока нет (Н. ТÓTH 2004: 49; BALÁZS 2015).

Существует, однако, интересная типологическая классификация европейских (в том числе и славянских) языков, которая основывается скорее на синтаксических параметрах, нежели на морфологических. Имеется в виду попытка Хаспельмата собрать доказательства о существовании лингвистического ареала, включающегося в себя романские, германские, балто-славянские, балканские и, более маргинально, западные угро-финские языки. Следуя термину Уорфа, этот ареал часто называют Языки среднеевропейского стандарта (СЕС) (Standard Average European) (HASPELMATH 2001: 1492). Хаспельмат пользуется двенадцатью параметрами, выбранными на основе следующих принципов:

(I) в подавляющем большинстве «ядерных» европейских языков данный признак существует; 
(II) в географически смежных языках (в кельтских, тюркских, восточных уральских, абхазо-адыгских и нахско-дагестанских) его нет;

(III) в восточных индоевропейских языках (в армянском, иранских и индийских) его нет;

(IV) данный признак существует в большинстве языков мира.

На такой основе Хаспельмат выделил следующие параметры:

- наличие определенного и неопределенного артиклей;

- относительные предложения с относительными местоимениями;

- форма перфекта с глаголом «иметь»;

- [выражение «экспериенцера» при помощи номинатива (чувства, восприятия и т.д.); $]^{1}$

- пассивная конструкция с пассивным причастием;

- [предпочтение производных декаузативных глаголов перед каузативами (типа иметь/иметься, встречать/встречаться и пр.;]

- выражение внешнего обладателя при помощи дательного падежа;

- отрицательные местоимения при отсутствии глагольного отрицания;

- использование частиц в сравнительных конструкциях;

- [эквативные конструкции на основе адвербиальных относительных предложений;]

- обязательное употребление субъектных местоимений;

- различение форм интенсификаторов и рефлексивов (ср. нем. selbst и sich) (HASPELMATH 2001: 1493-1501).

В результате применения приведенных параметров к языкам Европы получается своеобразная иерархия. В зависимости от того, сколько из девяти признаков, выбранных в конечном итоге, встречается в отдельных языках, Хаспельмат установляет, что ядром языков СЕС являются французский и немецкий (с 9 параметрами из 12), близко к ним стоят голландский, итальянский, испанский, португальский и албанский (по 8 параметров), а потом английский, румынский и греческий (по 7 параметров), шведский, норвежский, исландский и чешский (!) (по 6 параметров), литовский, латышский, венгерский, русский, украинский, польский, болгарский, сербский, хорватский и словенский (по 5 параметров). Остальные языки Европы, как например угро-финские (за

\footnotetext{
${ }^{1}$ Параметры в квадратных скобках не были включены Хаспельматом в конечный счет из-за отсутствия для них достаточной информации.
} 
исключением венгерского), турецкий, армянский, кельтские и кавказские языки не входят в языковой союз CEC (HASPELMATH 2001: 1505).

И сам Хаспельмат признает, что выбранные параметры не являются репрезентативными для европейских языков, так как они служат именно для иллюстрации и подтверждения гипотезы о языках СЕС. Кроме того, определение некоторых признаков для отдельных языков оспоримы, что может ослабить правдоподобность результатов. Также проблематична высокая степень субъективности и упрощенность анализа данных (ср. БАЛАЖ 2014: 172).

По поводу выше изложенной концепции Хаспельмата о языках СЕС важные уточнения добавил Томмола, по мнению которого признаки, предложенные как общие для европейских языков, не являются безусловно оптимальными для контрастивных исследований (TOMMOLA 2011). В своей статье он рассматривает все 12 параметров и их подтипы путем многочисленных примеров, обращая особое внимание на угрофинские и славянские языки, и установляет, что критерии, принятые для определения типичных европейских признаков, оказались до известной степени противоречивыми, а применение этих признаков иногда слишком прямым. Другими словами, игнорируется значительное варьирование в употреблении альтернативных средств для выражения тех или иных значений, например, в славянских языках (TOMMOLA 2011: 365).

К своему анализу Томмола прилагает таблицу с математически исчисленными статистическими корреляциями (величинами между -1 и $+1)^{2}$ между конкретными языками (см. ниже). На основе скалькулированных корреляций он приходит к значительным выводам, из которых я хочу здесь подчеркнуть лишь два: 1) среднее расстояние между родственными языками значительно меньше, чем их расстояние от других (неродственных) языков; 2) болгарский язык стоит далеко не только от угро-финских и германских языков, но и от русского, так как корреляция между болгарским и русским $(0,41)$ чуть больше корреляции между, например, русским и эстонским $(0,35)$. С другой стороны, болгарский язык проявляет высокую корреляцию относительно других славянских языков, особенно македонского $(0,87)$, сербского и хорватского, словацкого, польского, белорусского $(0,64)$ и чешского $(0,56)^{3}$.

Следует добавить, что незначительное число типологических отличий в морфологии и синтаксисе славянских языков объясняется не столько недостатками выше упомянутых средств и способов типологических исследований, а скорее тем фактом, что языки славянства по сей день остались в структурном отношении близкими друг к другу, поэтому генетическая связь между ними сильнее, чем различия в той или иной классификации.

\footnotetext{
${ }^{2}$ Чем больше это число, тем ближе друг к другу данные два языка.

${ }^{3}$ К сожалению, остальные славянские языки Томмола не включил в свой анализ.
} 


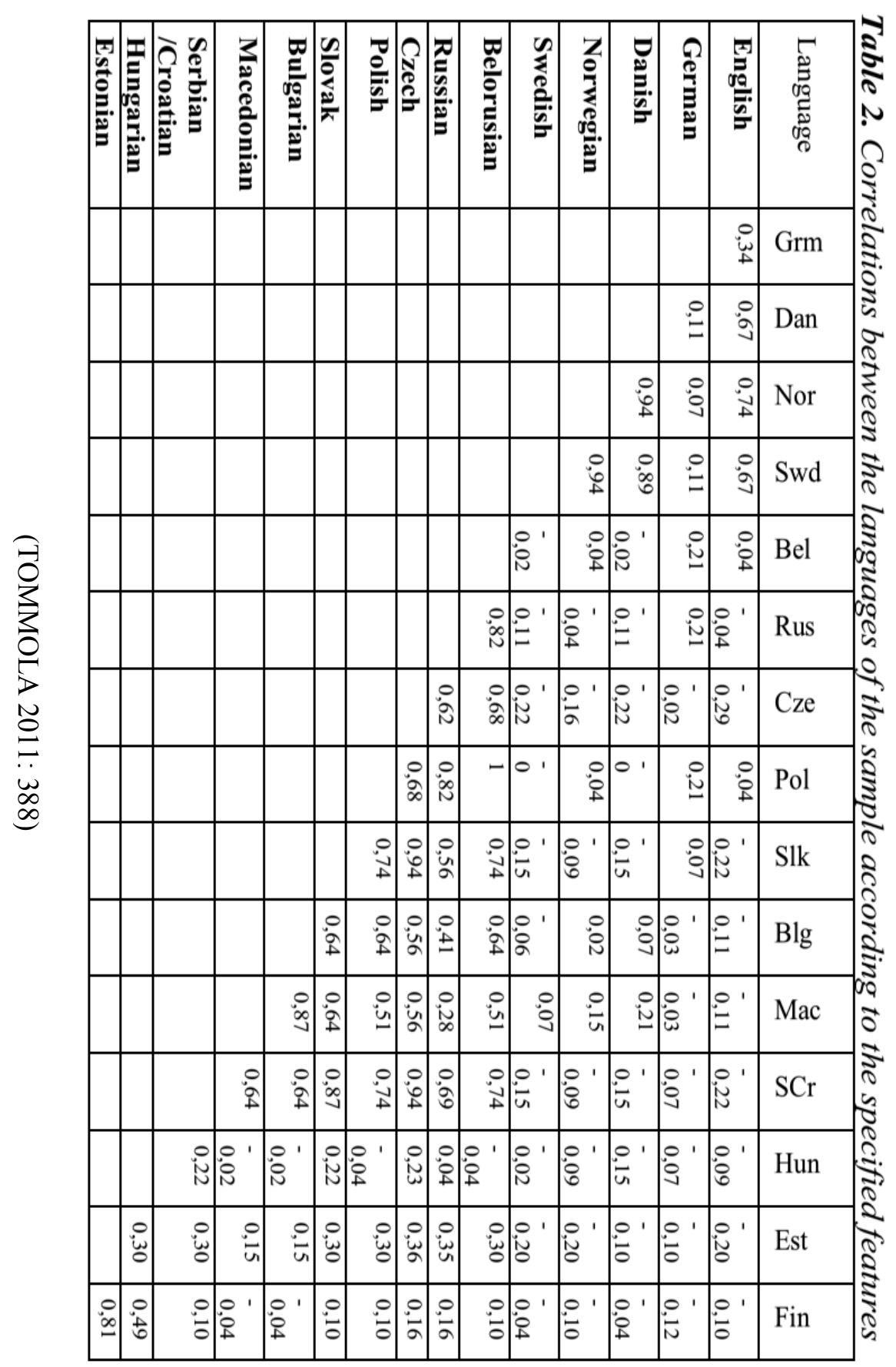




\section{Литература}

БАЛАЖ 2014 = Балаж Г.Л. Типологически стереотипи относно статуса на българския език // Studia Hungaro-Bulgarica, Tomus 3. Sumen - Szeged, 2014. 165-174.

ГЕРДЖИКОВ 1983 = Герджиков Г. Тенденцията към аналитизъм - определение, метод за измерване, причини, следствия // Съпоставително езикознание, 1983, № 5. 46-55.

ГЕРДЖИКОВ $1987=$ Герджиков Г. Неравномерният ход на развоя към аналитизъм в различните звена на системата и неговите причини // Втори международен конгрес по българистика. Доклади 2. История на българския език. София: БАН, 1987. 32-41.

МАСЛОВ 1986 = Маслов Ю.С. К характеристике болгарского языка с точки зрения морфологической типологии // Вопросы языка и литературы народов балканских стран: Межвуз. сб. Отв. ред. А.В. Десницкая. Ленинград: Издательство ЛГУ, 1986. 9-14.

СКАЛИЧКА 1966 = Скаличка В. К вопросу о типологии. ВЯ 1966, № 4. 22-30.

ARONSON 2007 = Aronson H.J. The Balkan Linguistic League, "Orientalism", and Linguistic Typology. Ann Arbor - New York: Beech Stave Press, 2007.

BALÁZS 2015 = Balázs L.G. „Superstable markers” in Slavic historical morphology // Балканско езикознание / Linguistique balkanique LIV, 2-3 (2015). 183-196.

BICKEL \& NICHOLS 2007 = Bickel B., Nichols J. Inflectional Morphology // Shopen T. (ed.) Language Typology and Syntactic Description, Volume III: Grammatical Categories and the Lexicon. Second Edition. Cambridge, 2007. 169-240.

GREENBERG $1960=$ Greenberg J.H. A quantitative approach to the morphological typology of language // International Journal of American Linguistics, vol. XXVI (1960), № 3. 178-94.

HASPELMATH $2001=$ Haspelmath M. The European linguistic area: Standard Average European // Language Typology and Language Universals. M. Haspelmath, E. König, W. Oesterreicher, W. Raible (eds.). Vol. 2, 2001. 1492-1510.

HASPELMATH $2009=$ Haspelmath M. An empirical test of the Agglutination Hypothesis // Universals of Language Today. Studies in Natural Language and Linguistic Theory. Vol. 76. Scalise, S. - Magni, E. - Bisetto, A. (eds.), 2009. 13-29.

H. TÓTH = H. Tóth I. Bevezetés a nyelvtudományba. Szeged - Szombathely, 2004.

PLANK 1999 = Plank F. Split morphology: How agglutination and flection mix // Linguistic Typology 3.3, 1999. 279-340.

PLUNGIAN 2001 = Plungian V.A. Agglutination and flection // Language typology and language universals: An international handbook (HSK), vol. 1, Haspelmath, M. et al. (eds). Berlin: de Gruyter, 2001. 669-678.

SAPIR 1921 = Sapir E. Language. An Introduction to the Study of Speech. New York: Harcourt, 1949.

SKALIČKA 1979 = Skalička V. Typologische Studien. Braunschweig/Wiesbaden: Vieweg, 1979.

TOMMOLA $2011=$ Tommola H. On Slavic and Finno-Ugric vs. Standard Average European // Formalization of Grammar in Slavic Languages. Potsdam Linguistic Investigations. P. Kosta, L. Schürcks (eds.). Frankfurt am Main/Berlin/Bern/Bruxelles/New York/Oxford/Wien: Peter Lang, 2011. 365-390. 
VELUPILLAI 2012 = Velupillai V. An Introduction to Linguistic Typology. Amsterdam/Philadelphia: John Benjamins, 2012.

WALS $=$ http://wals.info

WURZEL 1989 = Wurzel W.U. Inflectional Morphology and Naturalness. Dordrecht: Kluwer, 1989. 